\title{
Democratic Legitimacy and Proceduralist Social Epistemology
}

Fabienne Peter, Department of Philosophy, University of Warwick

Paper published in Politics, Philosophy, and Economics Politics, Philosophy and Economics 6 (3), 2007, 329-353.

\begin{abstract}
A conception of legitimacy is at the core of normative theories of democracy. Many different conceptions of legitimacy have been put forward - either explicitly or implicitly. In this paper, I shall first provide a taxonomy of conceptions of legitimacy that can be identified in contemporary democratic theory. The taxonomy covers both aggregative and deliberative democracy. I then argue for a conception of democratic legitimacy that takes the epistemic dimension of public deliberation seriously. In contrast to standard interpretations of epistemic democracy, however, the conception I put forward avoids procedure-independent standards of correctness. Instead, it relies on a procedural social epistemology and defines legitimacy entirely in terms of the fairness of procedures. I call this conception of democratic legitimacy "Pure Epistemic Proceduralism". I shall argue that it should be preferred over "Rational Epistemic Proceduralism", the conception of legitimacy that underlies the standard interpretation of epistemic democracy.
\end{abstract}

\section{Keywords}

legitimacy, deliberative democracy, epistemic democracy, social epistemology

\section{Acknowledgement}

For comments and discussions I am most grateful to Arun Abraham, Luc Bovens, Matthew Clayton, Jerry Gaus, Susan Hurley, Christian List, Herlinde Pauer-Studer, and Hans Bernhard Schmid, as well as to conference and seminar participants at the Max 
Weber Kolleg in Erfurt, the ECHE 2004 in Reims, the 2006 GAP conference in Berlin, the political theory group at Warwick, and the philosophy departments at LSE and Bristol. I would also like to thank two anonymous referees.

\section{Introduction}

It seems that a shift of interest is taking place in Anglo-American political philosophy a shift away from theories of justice and towards theories of democracy and political legitimacy. John Rawls' A Theory of Justice - published in the early 1970s - is widely seen as having lead to a proliferation of writings on justice. Independently of whether there is a causal link, his Political Liberalism - published in the early 1990s - coincides with the increased interest in democracy and political legitimacy expressed in the recent literature on deliberative democracy.

To be sure, the shift does not concern interest in normative issues. What it entails, rather, is a move away from a preoccupation with the question of what justice requires towards the normative requirements implicit in the idea of democracy. I take legitimacy to be the concept that captures the normative core of the idea of democracy. In A Theory of Justice, Rawls describes justice as the first virtue of social institutions (Rawls 1971: 3). According to this view, laws and institutions need to be just before we worry about such things as (utilitarian) efficiency. Democratic legitimacy, similarly, can be seen as the first virtue of collective decision-making. According to this view, such decisions have to be legitimate, before anything else. Democratic legitimacy establishes and qualifies the democratic assembly's right to rule by defining the terms for how the members of a democratic society ought to settle their disagreements about how to organize their life together (Christiano 2004). Such an interpretation of legitimacy is 
clearly normative. It consists of conditions that need to be satisfied for a democratic decision to be called legitimate. ${ }^{1}$

Democratic legitimacy, thus interpreted, has not played a major role in recent political philosophy until 15 years or so ago, when the literature on deliberative democracy started to emerge. The first batch of contributions to this literature explicitly distinguishes deliberative democracy from rival conceptions via an interpretation of the requirements of democratic legitimacy (e.g. Manin 1987, Cohen 1989, Benhabib 1994). In the past few years, an independent interest in the idea of political legitimacy can be observed. $^{2}$

It should not come as a surprise that as the literature on deliberative democracy and on democratic legitimacy increases rapidly, there is also an increasing diversity of conceptions of democracy and of interpretations of the requirements of legitimacy. To illustrate, is it essential for democratic legitimacy that a particular decision can be rationally justified or is it not? Whereas some take it for granted that it is, others argue against this requirement. My first aim in this paper is to sort out alternative interpretations of what democracy is about and of what legitimacy requires. I shall do so by providing a taxonomy by means of which alternative interpretations of the requirements of legitimacy can be distinguished. This part of the paper is retrospective. It defines and compares alternative conceptions of democratic legitimacy as they have been suggested in the recent literature on the theory of democracy. The taxonomy

\footnotetext{
${ }^{1}$ This normative interpretation of legitimacy differs from a Weberian descriptive interpretation. In the descriptive sense, legitimacy prevails as long as people support - or at least do not challenge - existing structures of authority. See Simmons (2001: $131 \mathrm{ff}$ ) for a discussion of these two interpretations of legitimacy. Democratic legitimacy, as I have defined it, is based on the terms specified by Rawls in Political Liberalism. It treats democratic legitimacy as a concept that is related to but weaker than justice and refers to the minimal conditions that the constitution of a democratic society has to satisfy. As such, my account of legitimacy differs from the one put forward by Simmons.

${ }^{2}$ E.g. Simmons (1999, 2001); Dryzek (2001); Buchanan (2002, 2004a); King (2003); Parkinson (2003); Arneson (2003); Chambers (2004); Christiano (2004).
} 
provides a simple way of classifying alternative conceptions of legitimacy and clarifies the issues that underlie current debates.

The second part of the paper is forward-looking. I shall use the taxonomy to identify and defend a particular conception of democratic legitimacy. I call it Pure Epistemic Proceduralism. It is based on a version of epistemic deliberative democracy. Epistemic democracy emphasizes the knowledge generating capacity of processes of collective decision-making. As a version of pure proceduralism, the conception I favor does not make legitimacy dependent on criteria that refer to the quality of the outcomes the procedure generates. Unlike the standard account of epistemic democracy, it refrains from making reference to procedure-independent standards of truth or correctness. Instead, it relies on a procedural social epistemology and defines legitimacy exclusively with respect to the fairness of democratic procedures. To my knowledge, this conception of legitimacy has not until now been defended explicitly. I shall argue, however, that the proposals of some theorists of democracy, for example Iris Marion Young's (1997, 2000), are best interpreted in terms of Pure Epistemic Proceduralism. In addition, I shall argue that Pure Epistemic Proceduralism should be preferred over the conception of legitimacy that is advocated in the standard account of epistemic democracy. I shall show that the epistemic commitments of this conception - I call it Rational Epistemic Proceduralism - are unnecessary and misleading.

\section{Conceptions of Democratic Legitimacy}

I propose a two-dimensional taxonomy to distinguish among alternative interpretations of the requirements of democratic legitimacy. A first dimension captures alternative ways of conceiving of democratic decision-making. In contemporary democratic theory, perhaps the two most important categories are those of aggregative and deliberative theories of democracy. The aggregative model finds its forerunners in Condorcet and 
Borda, but gained importance in contemporary democratic theory in the form of an economic theory of democracy through the works of Duncan Black (1958) and Kenneth Arrow (1963). The aggregative model focuses on mechanisms for aggregating (privately) expressed preferences - as through voting, for example - to a collective choice. Compared with aggregative democracy, deliberative democracy relies on a more comprehensive description of the process of democratic decision-making. It highlights the process of public discussion, in the course of which individual preferences may change.

In the recent literature, theories of epistemic democracy have again become important. ${ }^{3}$ In the epistemic interpretation, democratic processes are valued as knowledge producing processes. Epistemic democracy is compatible with both aggregative and deliberative democracy. An example of the former is used in the Condorcet Jury Theorem. The Jury Theorem, which will be discussed below, applies to the aggregation of beliefs about the correctness of alternative state of affairs - for example about what is truly in the common interest. The move from non-epistemic to epistemic aggregative democracy thus consists in a move from aggregating preferences about alternative social states to aggregating beliefs about them. The move from the standard interpretation of deliberative democracy to its epistemic variant, similarly, entails a shift in the account of what deliberation is conceived to be about and entails an acknowledgement of the epistemic value of the democratic process.

Combining the distinctions between aggregative and deliberative democracy, and between non-epistemic and epistemic interpretations yields four principal characterizations of the essential features of democratic decision-making: epistemic and non-epistemic aggregative democracy, and epistemic and non-epistemic deliberative

\footnotetext{
${ }^{3}$ See, among others, Cohen (1986); Estlund (1993, 1997, 2000); Gaus (1996, 1997); List and Goodin (2001); Goodin and Estlund (2004).
} 
democracy. These categories describe the first dimension of the taxonomy. The second dimension of the taxonomy captures different categories of requirements imposed on the democratic process in the name of legitimacy. Democratic theories differ in how much normative weight they place on procedures relative to substantive considerations about the quality of the outcomes of these processes. Conceptions of democratic legitimacy of a first category interpret the requirements of legitimacy exclusively in procedural terms. This is the category of "pure proceduralist" conceptions of democratic legitimacy. According to them, an outcome is legitimate if the democratic process satisfies certain conditions. These conditions are primarily conditions of "political fairness" or "political equality" (Beitz 1989). They demand that democratic decisions be the result of an equal consideration of individual interests. It is obvious that political equality takes on different forms in aggregative and deliberative democracy. Whereas the aggregative model requires giving equal consideration to all expressed preferences, the deliberative model is primarily concerned with people's possibilities to participate in the process of public deliberation.

A second category of conceptions of democratic legitimacy can be characterized by their inclusion of conditions that refer to the rationality of the outcomes of the democratic process in addition to procedural constraints. Approaches of this category, too, take fair procedures seriously; none of the approaches I shall discuss defends democratic procedures purely on instrumental grounds. ${ }^{4}$ For this reason, they cannot be called consequentialist. The emphasis of approaches in this category is on the ability of fair procedures to generate outcomes that satisfy certain rationality constraints. I shall call them "rational proceduralist".

\footnotetext{
${ }^{4}$ For a recent attempt to interpret democracy on the basis of purely instrumental values, see Arneson (2003).
} 
Along the first dimension, the taxonomy thus distinguishes between aggregative and deliberative democracy and, within each category, between epistemic and nonepistemic versions. Along the second dimension, it distinguishes between purely proceduralist approaches to democratic legitimacy and rational proceduralist approaches. Combining the two dimensions of the taxonomy yields a $4 \times 2$ matrix, into which alternative interpretations of the requirements of democratic legitimacy slot.

Luckily (for both author and reader), the taxonomy can be simplified a bit. The recent literature on epistemic democracy does not sharply distinguish between legitimacy requirements in its aggregative and deliberative variants. In my discussion of the conceptions of legitimacy implicit in this literature, this allows me to privilege the deliberative variant of epistemic democracy and discuss the legitimacy requirements for aggregative democracy as a variant thereof. Instead of going through all eight possible conceptions of democratic legitimacy of the taxonomy separately, I shall focus on the following six alternatives: (1) Pure Aggregative Proceduralism, (2) Rational Aggregative Proceduralism, (3) Pure Deliberative Proceduralism, (4) Rational Deliberative Proceduralism, (5) Rational Epistemic Proceduralism, and (6) Pure Epistemic Proceduralism. ${ }^{5}$

\begin{tabular}{|l|l|l|l|}
\hline & $\begin{array}{l}\text { Aggregative } \\
\text { Democracy }\end{array}$ & \multicolumn{2}{|l|}{ Deliberative Democracy } \\
\hline Pure Proceduralism: & Pure Aggregative & Pure Deliberative & \multicolumn{2}{l|}{ Pure Epistemic } \\
Fair Process & Proceduralism & Proceduralism & Proceduralism \\
\hline Rational Proceduralism: & Rational Aggregative & Rational Deliberative & Rational Epistemic \\
\hline
\end{tabular}

\footnotetext{
${ }^{5}$ The terminology is inspired by Estlund (Estlund 1997), but there are some important differences between his and my interpretation of some of these labels. Moreover, my terminology also differs from the one used by List and Goodin (2001). The simplified taxonomy suppresses epistemic variants of aggregative democracy. The complete taxonomy would have to include "Rational Epistemic Aggregative Proceduralism" and "Pure Epistemic Aggregative Proceduralism", and, for the sake of symmetry, would have to rename (5) and (6) to Rational Epistemic Deliberative Proceduralism, and Pure Epistemic Deliberative Proceduralism.
} 


\begin{tabular}{|l|l|l|l|}
\hline Fair Process and Rational & Proceduralism & Proceduralism & Proceduralism \\
Outcome & & & \\
\hline
\end{tabular}

In what follows, I shall explain these alternative interpretations. In the rest of this section, I shall focus on the first five interpretations, as they are fairly common in the current literature. The next section is dedicated to Pure Epistemic Proceduralism - an interpretation that the current debate has tended to overlook. I shall defend this particular interpretation of the requirements of democratic legitimacy over its rivals variants of Deliberative Proceduralism and Rational Epistemic Proceduralism.

\section{Aggregative Proceduralism}

Democratic theories of the aggregative variant focus on social decision mechanisms that aggregate individual preferences to a social choice. One can identify two interpretations of legitimacy in these theories. What I call Pure Aggregative Proceduralism is the view that some social decision rule - say majority rule - is fair because it gives equal consideration to all expressed preferences and that its outcome, whatever it might be, is politically legitimate for this reason. Arguments pointing in that direction can be identified in Robert Dahl's work, for example. ${ }^{6}$ Perhaps more importantly, the defense of Majority rule that follows from May’s theorem also falls into this category. ${ }^{7}$ Kenneth O. May (1952) shows that Majority rule is the only social decision rule that satisfies four minimal axioms. ${ }^{8}$ The work that these axioms do is to specify a fair democratic procedure. One of them in particular, the axiom of Anonymity, is a straightforward axiom of political equality, and May himself had called it the "Equality" condition

\footnotetext{
${ }^{6}$ See Dahl (1956). Dahl (1989), however, defends a view that is closer to Rational Aggregative Proceduralism.

${ }^{7}$ In a first draft of this paper, I had classified May’s theorem differently. I am grateful to seminar participants at LSE - in particular to Christian List and Alex Voorhoeve - for convincing me otherwise. ${ }^{8}$ The four axioms are: Decisiveness, Anonymity, Neutrality, and Positive Responsiveness. These labels are used in the contemporary literature and differ somewhat from May's original characterization. For a statement of May's theorem as it is used today, see Mueller (1989: 96ff).
} 
(May 1952). It demands that the social decision rule does not discriminate among persons. The other axioms are there to ensure that the equal consideration of individual preferences is indeed part and parcel of the decision process - not just a decorative sideshow.

To many aggregative democrats, such a set of conditions is not sufficient to guarantee legitimacy. In light of the possibility of Condorcet cycles, they argue, it is necessary to ensure that the aggregative mechanism adequately represents individual preferences and leads to meaningful social decisions. The problem is that if a Condorcet cycle occurs, decisions made through (binary) Majority rule will depend on the order in which alternatives are presented, and are thus not seen as a meaningful reflection of individual preferences. Arrow (1963) calls this problem the "voting paradox". To avoid the problem, variants of the second interpretation of democratic legitimacy in aggregative democracy include conditions for the quality of the outcomes chosen in addition to those specifying political equality. I call such conceptions of democratic legitimacy Rational Aggregative Proceduralism. The idea is that beyond being determined - through a democratic process - in the right way, the democratic decisions themselves have to be, in a certain sense, right. Arrow's formulation of the problem of social choice is an illustration of this second interpretation of aggregative democracy. In addition to axioms that capture the demands of a fair process, Arrow also imposes a rationality requirement on the outcomes of democratic decisions. Rational social choice, according to Arrow, is based on a social preference ranking that satisfies a set of consistency conditions akin to those imposed on individual preference rankings. $\mathrm{He}$ asks (Arrow 1963: 3): “Can we find ... methods of aggregating individual tastes which imply rational behavior on the part of the community and which will be satisfactory in other ways?" That is, can we find methods of collective decision-making which are both 
democratic (based on equal consideration of individual interests) and conducive to rational social choice? The rationality conditions are imposed to ensure that there are no cycles in the social preference ranking on which social choice is based. Arrow reasons that "in the voting paradox ..., if the method of majority choice is regarded as itself a value judgment, then we are forced to the conclusion that the value judgment ... is self-contradictory" (Arrow 1963: 5). In other words, Arrow argues that the possible irrationality of majority rule undermines its defense on the basis of political fairness.

Unfortunately, as it is well known, Arrow's impossibility theorem shows that there is no collective decision-making mechanism that satisfies all four axioms and consistently maps individual preferences into a social preference ranking. The theorem reveals that the difficulty exemplified by the voting paradox is a feature that affects a large class of aggregative mechanisms. As such, the impossibility theorem exposes the precariousness of democratic legitimacy in aggregative democracy. ${ }^{9}$

\section{Deliberative Proceduralism}

Deliberative democracy has often been advocated, not last, as a means to escape these difficulties with aggregative democracy. I do not, however, want to go into the details of the debate on aggregative vs. deliberative democracy here, and shall focus on deliberative democracy in what follows. ${ }^{10}$ Among conceptions of political legitimacy in deliberative democracy, a first distinction can be drawn between Pure and Rational Deliberative Proceduralism. I use these labels in analogy to those for aggregative democracy. This means that conceptions of the former category only impose a requirement of procedural fairness - specifically, of political equality - whereas the

\footnotetext{
${ }^{9}$ Riker (1982) interpreted Arrow's impossibility theorem as showing the impossibility not just of political legitimacy in aggregative democracy, but of legitimate democratic decision-making tout court. For comments on Riker, see Coleman and Ferejohn (1986) and Cohen (1986).

${ }^{10}$ For comparative assessments, see, for example, Knight and Johnson (1994); Cohen (1997); Dryzek and List (2003).
} 
latter add conditions that refer to the quality of the outcomes chosen. Whereas in aggregative democracy, political equality boils down to an equal consideration of expressed votes, in deliberative democracy, by contrast, those affected by a decision have to stand in a certain relation of substantive equality to each other in order for everyone's participation in public deliberation to enjoy a fair chance of being effective. They have to have access to deliberative fora to participate in public deliberation (e.g. the media) and they have to have the means to influence agenda-setting (Bohman 1996, 1997; Knight and Johnson 1997).

According to Pure Deliberative Proceduralism, legitimacy is ensured as long as the demands of procedural fairness are satisfied. Outcomes as such do not matter for political legitimacy under the regime of Pure Deliberative Proceduralism. All that matters for democratic legitimacy in such a regime is that collective decision-making proceeds through public deliberation among all those affected under some conditions of political fairness or equality. The view defended by Thomas Christiano in his book The Rule of the Many is an example for this category of political legitimacy. According to him,

"democratic discussion, deliberation, and decisionmaking under certain conditions are what make the outcomes legitimate for each person. ... [W] hatever the results of discussions, deliberation, and decisionmaking ..., they are legitimate. The results are made legitimate by being the results of the procedure" (Christiano 1996: 35).

Gerald Gaus also defends a variant of Pure Deliberative Proceduralism. He argues that the deliberative process inevitably produces disagreements which cannot be reconciled. Since agreement on a best solution is unlikely, there is no other justification for a particular decision to be had other than it being the result of a fair process: "In his or her 
deliberations, each citizen presents what he or she believes is the best public justification; the voting mechanism constitutes a fair way to adjudicate deep disagreements about what is publicly justified" (Gaus 1997: 234).

Adherents of Rational Deliberative Proceduralism hope to get more out of the democratic process. They envision that public deliberation will lead to a decision that all those affected can endorse, or at least that no one can reject with good reasons (Cohen 1989). In views of this kind, the justification of collective decisions is essential to democratic legitimacy. The requirement that the outcome of collective decisionmaking be rationally justified is thus added to that of political equality. Political legitimacy, according to conceptions that fall into this category, is not only "backwards looking" - towards the conditions under which a decision was reached - but also includes consideration of the rational quality of the outcomes chosen.

Rational Deliberative Proceduralism is the sister conception to Rational Aggregative Proceduralism. The notions of rationality invoked differ, however. In Aggregative Proceduralism, rationality demands some sort of consistency of social preferences or social choices. In Deliberative Proceduralism, rationality refers to the reasons given during deliberation in favor of or against certain alternatives.

In a strong version of Rational Deliberative Proceduralism, deliberation is characterized by the aim to generate a consensus, and legitimacy depends on the availability of shared reasons to support an outcome. ${ }^{11}$ Defences of deliberative democracy of this kind stress the rationalizing potential of public deliberation. The structure of such arguments is akin to what Rawls (1971: 85) has labelled "perfect proceduralism". There is an independently defined desirable outcome - a decision everyone has reasons to endorse - that is brought about by a particular procedure - a

\footnotetext{
${ }^{11}$ Some passages of Cohen (1989) seem to support this strong version of Rational Deliberative Proceduralism. See also Habermas, Benhabib (1994), and Postema (1995).
} 
fair deliberative process. An ideally fair deliberative process is necessary and sufficient to generate a rationally justified collective decision. For the sake of precision (and at the cost of terminological heaviness), conceptions of democratic legitimacy of this type can thus be labelled Rational Deliberative Perfect Proceduralism.

Many have doubted the ability of public deliberation to generate a consensus, even under ideal circumstances. ${ }^{12}$ Recent work on the so-called discursive dilemma reinforces this scepticism and raises doubts about the rationalizing potential of deliberative democracy. Philip Pettit and Christian List have shown how occurrences of the discursive dilemma may undermine the rationality of the outcome of public deliberations. ${ }^{13}$ This problem arises when the evaluation of alternative outcomes is logically connected to a set of independent premises. A tenure-decision may serve to illustrate the situation: tenure $(\mathrm{P})$ should be awarded if both teaching $(\mathrm{Q})$ and research (R) of the candidate are of sufficient quality. ${ }^{14}$ The dilemma turns on the possibility that a collective decision may clash with the independent collective evaluation of the individual premises, i.e. on the possibility that the committee's collective evaluation of $\mathrm{Q}$ (teaching) and R (research) implies "P" (tenure), whereas if asked directly, the collective would choose "not P" (no tenure). This can happen if the judgments of the three committee members are of the following form:

\begin{tabular}{|l|l|l|l|}
\hline & Teaching & Research & Tenure \\
\hline Member 1 & Yes & No & No \\
\hline Member 2 & No & Yes & No \\
\hline Member 3 & Yes & Yes & Yes \\
\hline Collective & Yes & Yes & Yes / No ? \\
\hline
\end{tabular}

\footnotetext{
${ }^{12}$ Gaus (1997) has a forceful argument against this view. Even Cohen (1989) grants that consensus might not be reachable.

${ }^{13}$ See Pettit (2001a, b); List and Pettit (2002, 2004).

${ }^{14}$ The example is from Bovens and Rabinowicz (2003).
} 
The choice-based procedure, which consists of a direct collective evaluation of the outcomes, and the premise-based procedure, which chooses the outcome implied by the collective evaluation of the premises may yield different decisions. ${ }^{15}$ If the former is chosen, the outcome cannot be backed up by the premises which would justify the choice. If the latter is chosen, this problem is avoided, but at the cost of imposing a decision that the collective would not have chosen, if asked directly.

In this account, rationality is interpreted as consistency between the evaluation of premises and the evaluation of outcomes. The discursive dilemma affects the demand that, to be legitimate, a collective decision has to be supported by reason. According to Pettit, the dilemma raises the question whether the "discipline of reason is meant to apply to each individual, taken singly, or to the group taken as a whole" (Pettit 2001b: 277). Clearly, if the first option is adopted, then the choices the collective makes cannot be backed up by the premises to which the decision is logically connected. If the second option is adopted, however, the individuals might have to accept a decision that they would not, collectively, have chosen.

While the discursive dilemma renders doubtful the harmony between fair procedures and rational outcomes on which Rational Deliberative Perfect Proceduralism is based, Pettit nevertheless insists on the importance of rationality for democratic legitimacy. Pettit thus does not resort to Pure Proceduralism. But because the dilemma draws attention to a possible source of irrationality in democratic decision-making, Pettit's interpretation of democratic legitimacy cannot be another example of perfect proceduralism. In the name of rationality, he is prepared to embrace the second horn of the dilemma. In his view, only the premise-based procedure will make a collective

\footnotetext{
${ }^{15}$ The labels for the two decision-making procedures are from Bovens and Rabinowicz (2003).
} 
agency "conversable" - answerable to reason. ${ }^{16}$ For legitimacy, Pettit's goal is thus to balance considerations of fairness with considerations of the quality of outcomes. With regard to the latter, his goal is to contain, as far as possible, the occurrence of inconsistencies between the evaluation of premises and the evaluation of the outcomes themselves. In my interpretation, his conception of democratic legitimacy thus serves to illustrate the subcategory of Rational Deliberative Imperfect Proceduralism.

\section{Rational Epistemic Proceduralism}

Some argue against Deliberative Proceduralism on the grounds that it says too little about why deliberative democracy is to be expected to yield good outcomes - better outcomes than, say, aggregative democracy. According to David Estlund (1997), the normative conditions imposed on deliberation should thus include an account of why it can be expected that deliberative decision-making will actually choose an outcome that is better or more just, insofar as it can be identified. This, he argues, introduces an epistemic dimension into deliberative democracy.

Joshua Cohen influentially characterized epistemic democracy through the following three properties (1986: 34): "an independent standard of correct decisions"; "a cognitive account of voting"; and "an account of decision-making as a process of the adjustment of beliefs". The first property assumes that, independently of the outcome of the democratic process, there is a sense in which a particular decision is correct - truly just or representing the common good. If this property applies, collective choices will qualify as either right or wrong and alternative institutionalizations of the democratic

\footnotetext{
${ }^{16}$ According to Pettit (2001a: 111): "every purposive group is bound to try to collectivize reason, achieving and acting on collective judgments that pass reason-related tests like consistency." This entails that "[u]nder the regime of deliberative democracy, it is required that with any logically connected propositions in the domain of discussion - the premises and conclusions of our examples - people make up their minds about the propositions in such a way that reason is satisfied" (Pettit 2001b: 276). See also List (2004) for a discussion of the conclusions Pettit draws from the discursive dilemma for collective rationality and democratic legitimacy.
} 
process will be seen as differing in their truth-tracking potential. The second property couples this account of the quality of the outcomes with an account of voting behavior, i.e. of the input to the democratic process. According to the cognitive account, "voting expresses beliefs about what the correct policies are ..., not personal preferences for policies" (Cohen 1986: 34). The third property, finally, applies to the democratic process itself. It demands that individuals adjust their beliefs about correct outcomes in light of the available evidence. Cohen thus concludes that "the epistemic conception treats processes of decision making as, potentially, rational processes of the formation of common judgments" (1986: 34).

Theories of epistemic democracy that build on Cohen's definition invoke the notion of rationality as truth or correctness. Emphasizing correctness can easily lead to anti-democratic conclusions. ${ }^{17}$ A simple, but not very compelling, epistemic conception would treat political legitimacy as ensured as long as the chosen outcome is "correct" for example, "truly" just or representing the common good - no matter how this choice is determined. Since such a consequentialist interpretation of legitimacy has no place in democratic theory, I want to leave it aside and focus instead on conceptions that recognize the importance of the procedural dimension and that try to stay within the democratic realm.

Variants of epistemic democracy of the kind that fit Cohen's definition have been articulated by Rousseau (1987 [1763]) and been invoked, more recently, in connection with the Condorcet Jury Theorem (Black 1958; Grofman and Feld 1988; List and Goodin 2001). The Condorcet Jury Theorem says that if there is a correct outcome, then, if all voters are more likely than not to identify that outcome, the probability that a majority will vote for that outcome increases with the size of the body

\footnotetext{
${ }^{17}$ For a discussion of this point, see Christiano (2001).
} 
of voters. Indeed, the larger the voting body, the more likely it is that the correct outcome will be chosen. It follows from the law of large numbers on which the Condorcet Jury Theorem rests that a majority is always more likely to be correct than a single individual, provided all individuals are more likely than not to be correct.

The interpretation of epistemic democracy as stated so far is a variant of aggregative democracy; it does not invoke deliberation. But Cohen's properties two and three are compatible with a deliberative process and a case for deliberative democracy can be constructed on the basis of the Condorcet Jury Theorem. It can be argued that public deliberation improves the formation of individual preferences by facilitating the exchange of reasons and information about the correct outcome. If this holds, it then follows in the context of the Condorcet Jury Theorem that compared to majority voting without deliberation, deliberative decision-making has a higher probability that the correct outcome will be chosen (Estlund 1989; Waldron 1989).

Drawing again on Rawls's distinction between perfect and imperfect procedural justice (Rawls 1971: 85f), the legitimacy requirement that is implicit in the interpretation of epistemic democracy just described can be called Rational Epistemic Perfect Proceduralism. It combines both features of perfect proceduralism that Rawls identified: there is a procedure-independent way of characterizing the correct outcome and there is a procedure which, ideally, leads to this outcome. According to this interpretation of democratic legitimacy, a collective decision is legitimate if it is correct. If competency is limited but above a certain threshold, a large number of people is more likely to chose the correct outcome than a single person. The democratic procedure is thus seen as instrumental in discovering correctness.

Estlund, who is perhaps the strongest defender of epistemic deliberative democracy, rejects Rational Epistemic Perfect Proceduralism - which he calls the 
"correctness theory of democratic legitimacy" (Estlund 1997: 180). He objects to this conception of legitimacy that it places too much weight on the correctness of outcomes and too little on the fairness of procedures. He argues, rightly in my view, that the probabilistic reasoning on which the Condorcet Jury Theorem rests cannot provide sufficient reasons to individuals for deferring their judgment to a majority decision. ${ }^{18}$ Estlund's own view is best described in analogy to Rawls' description of imperfect procedural justice, of which a trial is an example (Rawls 1971: 85f). The main goal of the trial process is to detect the truth (determined by an independent standard). Since this outcome cannot be guaranteed, it is typically demanded that the design of the trial process respects normative constraints related to procedural fairness. Estlund's description of democratic legitimacy rests on the same idea: there is an independent standard which determines the correct outcome, but since it cannot be expected that democratic procedures will identify it with certainty, the procedures themselves matter and have to satisfy certain normative criteria. Just like a person cannot be charged guilty on the grounds of probabilistic reasoning ("there is a $85 \%$ chance that you are guilty and we are thus convicting you"), they cannot, according to Estlund, be asked to submit their judgment on grounds of probabilistic reasoning ("there is a $85 \%$ chance that the majority correctly chose A, and while I thought B was correct, I now think that I must have been wrong").

Estlund calls his view "Epistemic Proceduralism”, but I shall call it Rational Epistemic Imperfect Proceduralism. This emphasizes that, like the "correctness theory" of democratic legitimacy, it is also a version of Rational Epistemic Proceduralism. It differs from the perfect proceduralist variant in that it recognizes possible shortcomings in the attempt to identify the correct outcome. To correct for this shortcoming, the

\footnotetext{
${ }^{18}$ Estlund also rejects Rational Deliberative Proceduralism. He argues that it either falls back on what I have called Pure Deliberative Proceduralism or, if it provides substance to the idea of justification, amounts to a version of Epistemic Proceduralism (Estlund 1997: 180).
} 
imperfect proceduralist variant combines the normative appeal of "correctness" with that of fair procedures. According to Estlund, "[d]emocratic legitimacy requires that the procedure is procedurally fair and can be held, in terms acceptable to all reasonable citizens, to be epistemically the best among those that are better than random" (Estlund 1997: 174). In this view, "correctness", if available, characterizes the goal and, ideally, the outcome of democratic decision-making, but it is not allowed to usurp the fairness of procedures. In both versions of Rational Epistemic Proceduralism, however, democratic legitimacy depends on the truth-tracking potential of the democratic process. For both it holds that the greater the truth-tracking potential, the more legitimate are its outcomes. The only difference between them is that Estlund's conception of democratic legitimacy demands less deference from individual participants to majority judgments than versions of Rational Epistemic Perfect Proceduralism do.

\section{Pure Epistemic Proceduralism}

According to Estlund, interpretations of deliberative democracy that do not refer to the epistemic dimension fail to show why deliberative democracy is better than rivaling approaches. And those interpretations of deliberative democracy that include a satisfactory account of how deliberative democracy can promote the common good and social justice are variants of Rational Epistemic Imperfect Proceduralism (Estlund 1997, 2000). The point is well taken that such an account has to be given. After all, participation in democratic decision-making should not be treated only as an end in itself. People will participate with the hope of addressing unresolved social problems and rectifying unjust situations. Variants of what I have called Pure Deliberative Proceduralism, which only emphasize procedural fairness, may fall short of substantiating this hope. 
A further problem with deliberative proceduralist conceptions is the tendency to demand that justice is fully realized prior to deliberation. The conditions imposed on the deliberative process in the name of securing effective equal participation tend to be very demanding. This amounts to putting the cart before the horse. If realizing justice is a plausible task for deliberative democracy, an account has to be given of how it can be expected that deliberative democracy will actually achieve this task; it will not do to simply pack justice into the conditions for legitimate deliberation. ${ }^{19}$

While I accept at least part of Estlund's case for taking seriously the epistemic dimension, I reject his proposal for how this should be done. His interpretation of epistemic democracy endorses all three properties identified by Cohen (1986). It assumes an independent standard of correct decisions, adopts a cognitive account of voting, and views deliberation as a process of adjusting beliefs. I do not think that this characterization is the best way for thinking about the epistemic dimension of deliberative democracy. Estlund is at pains to emphasize the importance of procedural fairness and to minimize reliance on procedure-independent standards, but, true to Cohen's first property, his proposal nevertheless takes correctness to be a procedureindependent criterion for the quality of the outcomes of collective decision-making. He is the first to concede that importing correctness into the philosophy of democracy is a difficult endeavor. He cautions: "The moral challenge for any epistemic conception of political authority ... is to let truth be the guide without illegitimately privileging the opinions of any putative experts" (2000: 183). I am not convinced, however, that Rational Epistemic Proceduralism can meet this challenge.

The main problem with Rational Epistemic Proceduralism is that it underestimates the epistemic value of democratic procedures themselves. According to

\footnotetext{
${ }^{19}$ Bohman's account, for example, exhibits this tendency when he writes about "political poverty" economic inequalities that undermine effective access to the public sphere (see Bohman 1996). I deal with this issue in a separate paper (Peter 2007).
} 
Estlund, "procedural fairness ... is not a cognitive process" (1997: 196). He and many other writers on epistemic democracy take it for granted that an account of how democratic procedures are able to track an independently determined correct outcome, if one exists, is what renders a theory of democracy epistemic, as opposed to discursive. The epistemology underlying this assumption is not questioned. It is a social epistemology of the variant that Alvin Goldman has called a veritistic consequentialist epistemology. A veritistic epistemology "is concerned with the production of knowledge, where knowledge is ... understood in the 'weak' sense of true belief" (1999: 5). As a consequentialist social epistemology, it is concerned with the effect of social practices on epistemic (veritistic) value, i.e. with how they promote or impede the acquisition of knowledge (Goldman 1999: 87). The democratic process would be an example of such a social practice. It follows from this epistemology that alternative institutional arrangements for a fair democratic process should be evaluated in relation to their contribution to veritistic value; to their truth-tracking potential. In this light, Estlund's project can be characterized as an attempt to reconcile, within the conception of democratic legitimacy, a non-consequentialist concern with fair procedures with a consequentialist concern with truth-tracking.

Veritistic consequentialist epistemology is not, however, the only conceivable social epistemology. The contenders are alternative consequentialist epistemologies and, as Goldman also notes, proceduralist social epistemology. ${ }^{20}$ According to Goldman, proceduralist epistemology focuses exclusively on "the intrinsic merits of intellectual practices to judge their epistemic worth or propriety" (1999: 75). It defines knowledge as what results from an appropriately designed process of inquiry. It dispenses with the idea that a procedure-independent standard is necessary to assess the quality of the

\footnotetext{
${ }^{20}$ The epistemology underlying Habermas' (1990 and 1996) interpretations of deliberative democracy he qualifies as "consensus consequentialism" (Goldman 1999: 69).
} 
knowledge-producing practices. As a social epistemology, it acknowledges social influences on processes of knowledge production, but addresses them not through an instrumental valuation, but as constitutive of inquiry. Finally, in the way in which I use the term, social epistemology is a normative project. Some strands in Post-Kuhnian science theory have gone natural in Quine's sense and take a descriptive stance towards epistemic practices and the resulting knowledge claims. Interpreted normatively, a procedural approach to social epistemology is concerned with the conditions that knowledge-producing practices should satisfy. Epistemologies that fit my definition have been developed by many social epistemologists, but most notably by feminist epistemologists and philosophers of science (e.g. Longino 1987, 2002; Harding 1991, 1998).

A procedural approach to social epistemology consists of a set of criteria that apply to the knowledge producing practices directly. Because it would be beyond the scope of this paper to discuss this in detail, I shall limit myself to a brief characterization of the accounts that have been proposed by Sandra Harding and Helen Longino. Harding's starting-point is standpoint-epistemology, according to which knowledge claims are constitutively perspectival and dependent on particular social positions. Longino (2002) views cognition itself as a social process. She argues against views based on a dichotomy between "the rational" and "the social" - between what can be known (the truth) and what is known (the product of social processes that are better or worse truth-trackers). Instead, like Harding, she is interested in the features of the process of knowledge production and argues that normativity ought to be attached to these features themselves and not to the quality of the outcomes of this process. Her argument rests on a distinction between three senses of knowledge: (i) knowledgeproducing practices; (ii) knowing; and (iii) the content of knowledge, outcome of 
knowledge-producing practices (Longino 2002: 77f). Strands in science studies that represent the "social" side of the dichotomy interpret all three in social terms: knowledge-producing practices are a set of social practices, and knowing and the content of knowledge depends of what is seen as acceptable in those social settings. Those on the "rational" side of the dichotomy - traditional epistemology - look at knowledge-producing practices from the angle of processes of belief acquisition that justify belief. Knowing and the content of knowledge, meanwhile, the other two senses of knowledge, are defined directly, independently of processes of belief acquisition.

Longino's hybrid view holds on to the idea that there are normative criteria that apply to knowledge-producing practices, but defines knowing and the content of knowledge in relation to these processes. She challenges the individualism of traditional epistemology and argues that knowledge-producing practices ought to be viewed as both normative and social. Her alternative account,

"locates justification, or the production of knowledge, not just in the testing of hypotheses against data, but also in subjecting hypotheses, data, reasoning, and background assumptions to criticisms from a variety of perspectives. ... Because the assumptions that constitute the intellectual context of observation and reasoning are, by their nature, usually not explicit but tacit patterns of thought, the function of critical interaction is to make them visible as well as to examine metaphysical, empirical, and normative implications. These discursive practices are both constructive and justificatory. ... Sociality does not come into play at the limit of or instead of the cognitive. Instead, these social practices are cognitive" (Longino 2002: 205).

Her epistemology is procedural because it dispenses with procedure-independent criteria for what counts as knowing or for what defines the content of knowledge. It is 
normative, and not just social, because it has a set of criteria that distinguishes among knowledge-producing practices and knowing and its content depend on the appropriateness of the procedure of which they are the outcomes.

Both Harding and Longino demand that knowledge claims can be scrutinized from a variety of perspectives and that it is possible to subject the background assumptions on which they rest to criticism. Harding's criterion of epistemic inclusiveness requires that perspectives from different social positions are adequately represented in knowledge producing processes. $^{21}$ She calls this - procedural - criterion “strong objectivity" (Harding 1991, chapter 6).

Longino (2002: 128ff) has a list of conditions that processes of knowledge production should fulfill. She proposes four such conditions. The first, "publicly recognized forums for the criticism of evidence, methods, and of assumptions and reasoning" demands that criticism of original research is not marginalized. This criterion is concerned with creating space for critical discourse - whithin the venues of original research. The second, "uptake of criticism", addresses the transforming potential of critical discourse. Uptake is understood as cutting both ways: i.e. both defenders of a certain knowledge claim and its critics should be responsive to each other. The third criterion demands "publicly recognized standards by reference to which theories, hypotheses, and observational practices are evaluated and by appeal to which criticism is made relevant to the goals of the inquiring community." Public, not just implicit, standards, help both defenders of a certain claim and their critics to identify their points of agreement and disagreement and structure the process in which arising problems are handled. This criterion ensures that critical discourse is orderly and

\footnotetext{
${ }^{21}$ Harding demands that "the sciences need to legitimate within scientific research, as part of practicing science, critical examination of historical values and interests that may be so shared within the scientific community, so invested in by the very constitution of this or that field of study, that they will not show up as a cultural bias between experimenters or between research communities" (Harding 1991: 146f).
} 
constructive, rather than chaotic and destructive. Longino adds that these standards need no be static, but can themselves come under scrutiny. Finally, she lists "tempered equality ... of intellectual authority", a criterion that warns of illegitimate associations between social, political, and/or economic privilege and power with epistemic privilege and power.

While originally developed in the context of scientific inquiry, these procedural approaches are applicable to the context of democratic theory. They offer a way of incorporating the epistemic dimension into a concern with fair procedures by stressing the epistemic value of fair deliberative processes. In the remainder of this paper I shall sketch an interpretation of epistemic deliberative democracy that relies on such a proceduralist epistemology and defend the corresponding conception of democratic legitimacy.

The interpretation of deliberative democracy I want to advocate conceives of the subject of deliberation as not limited to the giving and taking of reasons for and against different courses of social action, but as extending to the public examination of the knowledge basis on which public reasoning about policy alternatives rests - the knowledge claims themselves and the processes by which they have been generated. This honors the knowledge-producing potential of democratic decision-making and makes the account of democracy distincly epistemic. But whereas the standard account of epistemic democracy as put forward by Joshua Cohen, makes reference to a procedure-independent standard of correctness, I propose to interpret the epistemic dimension procedurally and to avoid trying to balance non-consequentialism about democratic participation with consequentialism about knowledge.

The resulting conception of democratic legitimacy, Pure Epistemic Proceduralism, requires public deliberation among all those affected under conditions of 
political and epistemic fairness. In Pure Epistemic Proceduralism, diverging individual interests must bee considered fairly in the deliberative process on the basis of a fair consideration of evidence. This conception of democratic legitimacy lies in between Rational Epistemic Proceduralism and Pure Deliberative Proceduralism. While Pure Deliberative Proceduralism and Pure Epistemic Proceduralism are alike in that they both define legitimacy purely on the basis of procedural fairness, they differ in that latter includes, on their own right, criteria that specify epistemic fairness. It includes, for example, not just criteria refering to equal possibilities to participate in the deliberation over given policy proposals, but also criteria that regulate public deliberation at the factgathering and analyis stages of processes of policy formulation. Pure Epistemic Proceduralism is thus distinct from variants of Deliberative Proceduralism in that it explicitly refers to the epistemic dimension. But because it does so in a proceduralist way, it also differs from Rational Epistemic Proceduralism and I shall argue in a moment that it is preferable to Rational Epistemic Proceduralism.

Pure Epistemic Proceduralism has not, until now, been defended as a distinct alternative to the views I have described in the first part of the paper, but it is compatible with some interpretations of deliberative democracy that have been put forward. The epistemic value of public deliberation is highlighted in Amartya Sen's work on democracy, for example (Sen 1999a, b). He calls this democracy's constructive function, to be seen as in addition to the intrinsic and instrumental values connected to fair procedures, and he characterizes it without making recourse to a procedureindependent standard of correctness. In his words (1999b: 3):

"the practice of democracy gives the citizens an opportunity to learn from each other .... Even the idea of 'needs' (including the understanding of 'economic needs') requires public discussion and exchange of information, views and 
analyses. In this sense, democracy has constructive importance, in addition to the intrinsic value it has in the lives of the citizens and its instrumental role in political decisions.",22

Pure Epistemic Proceduralism, I contend, also provides the appropriate normative framework for Iris Marion Young's interpretation of deliberative democracy (Young 1989, 1996, 1997, 2000). Young addresses the question as to how it can be expected that deliberative democracy is a good means to reach justice. Her answer explicitly invokes the epistemic dimension: the „structure and norms of ideal deliberative democracy ... provide the epistemic conditions for the collective knowledge of which proposals are most likely ... to promote results that are wise and just" (Young 2000: 30; my emphasis). Young's argument is directed against the way in which some (non-epistemic) versions of deliberative democracy tend to discuss the requirement of an orientation towards the common good. She fears that appeals to the common good will - intentionally or not - silence certain perspectives. She writes (2000: 81):

„Social movements mobilizing around experiences and analyses of the oppressive and unequal consequences of social differentiations of gender, race, sexuality, national origin, or religion, along with class, have expressed skepticism about appeals to a common good. ... Issues of justice vary for structurally different groups, this politics of difference argues; oppressions and wrongful inequalities take many forms, and appeals to a common good do not adequately respond to and notice such differences."

The crucial point of Young's argument in the context of this paper is that social differences matter epistemically. Her worry about appeals to the common good can be

\footnotetext{
${ }^{22}$ See also Anderson (2003) for a discussion of Sen's theory of deliberative democracy. Elements of a pure epistemic proceduralist conception of deliberative democracy and legitimacy can be identified in Valadez (2001) as well.
} 
interpreted in terms of the tacit understandings about common knowledge that are underlying appeals to the common good and that are not themselves subject to democratic scrutiny. If experiences and analyses of the consequences of injustice will vary for social groups, deliberation needs to take this situatedness of knowledge into account. Public deliberation, then, is not just about the common good, but extends to the epistemic bases on which people reason about the common good. On these grounds, Young (2000) argues that "difference" should be seen as a resource for deliberative democracy if it is to fulfill its goal of inclusive public reasoning.

Pure Epistemic Proceduralism captures these intuitions about the epistemic value of democratic processes and assigns them a place in the landscape of alternative conceptions of democratic legitimacy. It leads to an interpretation of Young's theory of deliberative democracy that is epistemic in the sense that it treats public deliberation as a knowledge-producing process. But it dissociates it from the standard account of epistemic democracy in that it does not refer to procedure-independent standards of correctness. The interpretation of Young's account I want to suggest treats her insistence on inclusiveness as being based, in part, on criteria of epistemic fairness.

I now want argue that interpreting Young's theory of democracy as resting on Pure Epistemic Proceduralism is indeed a coherent alternative to an interpretation based on Rational Epistemic Proceduralism. Moreover, I want to argue that Pure Epistemic Proceduralism is preferable to Rational Epistemic Proceduralism because the latter commits us to unnecessary problematic claims about the epistemic dimension of democratic legitimacy. Specifically, I want to raise three objections against Rational Epistemic Proceduralism: (i) that it is not a practicable conception of legitimacy, (ii) that it is not necessary, and (iii) that it is normatively misleading. 
A first problem with Rational Epistemic Proceduralism, as Estlund is well aware, is that correctness is difficult to determine. Judgments about correctness tend to be fallible and historically and socially situated. Correctness thus seems primarily something to aspire to, but not something that is ever at hand. There are, in other words, only claims about correctness - judgments and beliefs; correctness itself, interpreted as a procedure-independent notion, is elusive. If a procedure-independent standard is elusive, however, it is difficult to see how democratic legitimacy can hinge on its normative cutting power.

In reply, Estlund might say that we know enough about correct outcomes to design the democratic process in such a way as to increase its ability to track them. These processes should be fine-tuned, as far as the fairness constraint allows it, to maximize their truth-tracking potential. For example, if it is known that certain biases e.g. sexism or racism - tend to detract from correctness, then legitimacy requires that the democratic processes be designed in such a way as to curtail their effects on the outcomes.

It seems obviously right to demand that biases judged harmful need to be contained for legitimacy. But the crucial question is whether the way in which Rational Epistemic Proceduralism recommends that we do this is right. I do not think it is and this leads me to my second objection to Estlund's proposal. To fix ideas, I want to discuss a distinction that Rational Epistemic Proceduralism makes between two possible outcomes of fair processes. It distinguishes between, on the one hand, the case where a fair process leads to a correct outcome and, on the other, the case where a fair process leads to a biased outcome. The first is qualified as legitimate, whereas the second fails to ensure legitimacy. Unfair processes, of course, would qualify as illegitimate - 
independently of the outcomes they generate. On this, Rational Epistemic Proceduralism and Pure Epistemic Proceduralism concur.

I do not find the differential treatment of the outcomes of fair processes plausible. For how should one make sense of the idea of a fair deliberative process that leads to a biased outcome? To give an example, suppose the outcome of collective decision-making is sexist. It endorses a policy proposal that claims to increase the common good or social justice but rests on sexist premises about family life. Now, a fair procedure should ensure that everybody is able to participate in the process as an equal. It should enable all those affected by and opposed to sexism to effectively challenge these premises - Longino's criterion of uptake of criticism that I discussed above underlines this demand. If the procedure is genuinely fair, one would thus not expect a sexist proposal to go through. Conversely, if a sexist proposal goes through, is this not likely to be the result of unfair procedures, in which women may have been nominally treated as equals, but not effectively so? I find it difficult to see how a deliberative process can be called fair if deliberation over policy alternatives leaves unchallenged background assumptions that undermine the equal standing of all participants. But if the procedure is unfair, then we do not need Rational Epistemic Proceduralism to explain the lack of legitimacy of the outcome. It will be sufficient to argue that the procedures did not meet the standards of procedural fairness. In this - purely proceduralist view bias is treated not as an additional concern, but as a part of the very concern with procedural fairness. My second objection to Estlund's proposal is thus that the assumption of a procedure-independent standard of correctness is unnecessary to address his concerns. The illegitimacy of a biased outcome can be attributed to unfair procedures. This renders Pure Epistemic Proceduralism more parsimonious than Rational Epistemic Proceduralism. 
Thirdly, and relatedly, there is the question of how to avoid the problem of "privileging the opinions of any putative experts" of which Estlund rightly warns us. The truth-tracking view commits us to a strategy of bias-avoidance. The very idea of there being a correct outcome demands that this outcome be neutral. At first sight, Rational Epistemic Proceduralism may thus seem to avoid this problem, as it would call illegitimate any outcome that is not correct, but chosen under the influence of biased "experts". The alternative view is the one that is also stressed by Young: to treat difference not as something to be eliminated from, but as a resource for knowledge production. According to this view, social influences of all sorts are always present in epistemic practices - be it in science or in other contexts - and not all such influences need to be valued negatively. Which biases are and which are not harmful is left to be determined in an inclusive process. In the example above, it trusts that sexist premises will be more effectively challenged from the vantage point of a - biased - feminist perspective than from the vantage point of - bias-neutral - truth.

The advocate of the truth-tracking view can reply to this that if it is known that the inclusion of feminist values and beliefs improves the truth-tracking potential of the knowledge producing process, then it would also recommend including them. ${ }^{23}$ But that is not a satisfactory solution. It leaves out the issue of how we learn about biases in the first place. The problem is that even if we know what potential sources of bias are - e.g. values and beliefs related to gender - we will not know in every instance how these biases influence deliberation. This is so because bias-inducing values and belief typically operate at the level of background assumptions - i.e. as part of the frame of inquiry, but not as its objects. The truth-tracking view can only contain those biases about which a sufficient amount is already known, so that the process of inquiry can be

\footnotetext{
${ }^{23}$ I thank an anonymous referee for suggesting this reply to me.
} 
fine-tuned accordingly. The truth-tracking account only becomes effective, so to speak, "after the fact" - once it is considered established how a bias operates. This overlooks how the discovery of biased background assumptions and how they operate is typically a contested process - it overlooks what Sen labels the constructive value of democracy. The biases-as-resource view, by contrast, is concerned precisely with this process. It emphasizes that the problematic biases are not those we already know about, but those that remain hidden. As such, it manifests more caution about possible biases than the bias-avoidance view with its dependence on the neutrality of a correct outcome and warns against smothering the process of discovery through claims to correctness. The bias-avoidance strategy, to put the point bluntly, bets on the wrong horse.

This third objection is the most serious. It challenges Estlund's version of Rational Epistemic Proceduralism for being normatively misleading. The difference between the two views is that the bias-avoidance view is part of a consequentialist epistemology, whereas the biases-as-resources view is part of a proceduralist epistemology. As part of a consequentialist epistemology, the bias-avoidance view values biases instrumentally in relation to their truth-tracking potential. It can deal with biases only insofar as their effects on the correct outcome are already known. The biasas-resources view demands that knowledge producing practices be as inclusive and as public as possible, to facilitate contestation from a multitude of perspectives. It values procedural fairness from the epistemic point of view as well; political and epistemic fairness are just two sides of the same coin.

\section{Concluding Remarks}

The conception of democratic legitimacy I have defended in this paper emphasizes that there are epistemic and non-epistemic reasons to value deliberative democracy. The standard account of deliberative democracy focuses on non-epistemic reasons - such as 
reciprocal justification, for example - and brackets the issue of epistemic values. Estlund has criticized this standard interpretation and argued that we should value deliberative democracy for epistemic reasons as well and conceive of the requirements of democratic legitimacy accordingly. In his account, the epistemic reason for valuing deliberative democracy lies in its truth-tracking potential. I agree with Estlund that deliberative democracy is valuable for both epistemic and non-epistemic reasons. But I have argued that the two need not be seen as conceptually independent. I have used my taxonomy of alternative conceptions of democratic legitimacy to show how Rational Epistemic Proceduralism is not the only possible conception of legitimacy in epistemic democracy. Pure Epistemic Proceduralism is a coherent alternative conception.

My goal has been to show how Pure Epistemic Proceduralism, because it does not presuppose the existence of a correct outcome for democratic decisions, alleviates some of the problems that Rational Epistemic Proceduralism creates, while accommodating the concerns Rational Epistemic Proceduralism aims to address with fewer epistemological commitments. My argument shows that making democratic legitimacy depend on correctness is not necessary and possibly misleading because it is content with the elimination of biases we already know and may smother the process of discovery of biases not yet recognized. The account I presented rests on a link between procedural fairness and epistemic value. More so than alternative interpretations of epistemic democracy, it gives a grip on the idea that inclusive public deliberation is valuable not just for the ideal of political fairness that it embodies, but also for its epistemic contribution. Of course, much more would have to be said about the exact nature of the conditions of political and epistemic equality that this conception of democratic legitimacy imposes, but this will have to be done in another paper. 


\section{References}

Anderson, Elisabeth. 2003. "Sen, Ethics, and Democracy." Feminist Economics 9(2-3): $239-261$.

Arneson, Richard. 2003. "Debate: Defending the Purely Instrumental Account of

Democratic Legitimacy.” The Journal of Political Philosophy 11(1): 122 - 132.

Arrow, Kenneth J. (1963): Social Choice and Individual Values. Second Edition. New

Haven \& London: Yale University Press.

Beitz, Charles R. 1989. Political Equality. Princeton: Princeton University Press.

Benhabib, Seyla. 1994. "Deliberative Rationality and Models of Democratic

Legitimacy." Constellations 1(1): 25 - 53.

Black, Duncan 1958. The Theory of Committees and Elections. Cambridge:

Cambridge University Press.

Bohman, James. 1996. Public Deliberation. Cambridge: MIT Press.

Bohman, James. 1997. "Deliberative Democracy and Effective Social Freedom:

Capabilites, Resources, and Opportunities.” In Bohman, James and William Rehg (eds.)

Deliberative Democracy: Essays on Reason and Politics. Cambridge, Mass.: MIT

Press, pp. $321-348$.

Bohman, James. 1998. "The Coming of Age of Deliberative Democracy.” Journal of Political Philosophy 6: 399 - 423.

Bovens, Luc and Wlodek Rabinowicz. 2003. "Democracy and Argument - Tracking Truth in Complex Social Decisions." In Anne van Aaken, Christian List, and Christoph Lütge (eds.) Deliberation and Decision. Aldershot: Ashgate Publishing.

Buchanan, Allen. 2002. "Political Legitimacy and Democracy. "Ethics 112(4): 689 719. 
Buchanan, Allen. 2004a. Justice, Legitimacy, and Self-Determination. Oxford: Oxford University Press.

Buchanan, Allen. 2004b. "Political Liberalism and Social Epistemology." Philosophy and Public Affairs 32(2): 95 - 130.

Chambers, Simone. 2004. "Democracy, Popular Sovereignty, and Constitutional Legitimacy." Constellations 11(2): 153 - 173.

Christiano, Thomas. 1996. The Rule of the Many: Fundamental Issues in Democratic Theory. Boulder, Co.: Westview Press.

Christiano. Thomas. 2001. "Knowledge and Power in the Justification of Democracy." Australasian Journal of Philosophy 79(2): $197-215$.

Christiano, Thomas. 2004. "The Authority of Democracy." The Journal of Political Philosophy 12(3): $266-90$.

Cohen, Joshua. 1986. “An Epistemic Conception of Democracy.” Ethics 97(1): 26 - 38.

Cohen, Joshua. 1989. “Deliberation and Democratic Legitimacy.” In Hamlin, Alan and Philip Pettit (eds.) The Good Polity. Oxford: Blackwell, pp. 17 - 34.

Cohen, Joshua. 1997. "Procedure and Substance in Deliberative Democracy." In Bohman, James and William Rehg (eds.) Deliberative Democracy: Essays on Reason and Politics. Cambridge: MIT Press, 407 - 437. Reprinted from Benhabib, Seyla (ed.) Democracy and Difference. Princeton: Princeton University Press, pp. 95 - 119. Coleman, Jules and John Ferejohn. 1986. "Democracy and Social Choice.” Ethics 97(1): $6-25$.

Dahl, Robert. A. 1956. A Preface to Democratic Theory. Chicago: Chicago University Press.

Dahl, Robert A. (1989): Democracy and Its Critics. New Haven and London: Yale University Press. 
Dryzek, John. 2001. "Legitimacy and Economy in Deliberative Democracy.” Political Theory 29(5): $651-669$.

Dryzek, John S. and Christian List. 2003. "Social Choice Theory and Deliberative Democracy: A Reconciliation.” British Journal of Political Science 33(1): 1 - 28. Estlund, David. 1989. "Democratic Theory and the Public Interest: Rousseau and Condorcet Revisited.” American Political Science Review 83: 1317 - 1322.

Estlund, David. 1993. "Making Truth Safe for Democracy." In Copp, David, Jean Hampton, and John E. Roemer (eds.) The Idea of Democracy. Cambridge: Cambridge University Press, pp. $71-100$.

Estlund, David. 1997. "Beyond Fairness and Deliberation: The Epistemic Dimension of Democratic Authority." In Bohman, James and William Rehg (eds.) Deliberative Democracy: Essays on Reason and Politics. Cambridge: MIT Press, pp. 173-204. Estlund, David. 2000. “Political Quality.” In Paul, Ellen Frankel, Fred D. Miller, and Jeffrey Paul (eds.) Democracy. Cambridge: Cambridge University Press, pp. 127 - 160. Gaus, Gerald F. 1996. Justificatory Liberalism: An Essay on Epistemology and Political Theory. Oxford: Oxford University Press.

Gaus, Gerald F. 1997. "Reason, Justification, and Consensus: Why Democracy Can’t Have It All.” In Bohman, James and William Rehg (eds.) Deliberative Democracy: Essays on Reason and Politics. Cambridge: MIT Press, pp. 205 - 242.

Goldman, Alvin. 1999. Knowledge in a Social World. Oxford: Oxford University Press. Goodin, Robert and David Estlund. 2004. "The Persuasiveness of Democratic Majorities.” Politics, Philosophy \& Economics 3(2): 131 - 142.

Grofman, Bernard and Scott L. Feld. 1988. "Rousseau's General Will: A Condorcetian Perspective." The American Political Science Review 82(2): 567 - 76. 
Habermas, Juergen. 1990. Moral Consciousness and Communicative Action. Transl. by

Christian Lenhardt and Shierry Weber Nicholsen. Cambridge: MIT Press.

Habermas, Juergen. 1996. Between Facts and Norms. Transl. by William Rehg.

Cambridge: MIT Press.

Harding, Sandra. 1991. Whose Science? Whose Knowledge? Thinking from Women's

Lives. Ithaca: Cornell University Press.

Harding, Sandra. 1998. Is Science Multicultural? Bloomington and Indianapolis:

Indiana University Press.

King, Loren A. 2003. "Deliberation, Legitimacy, and Multilateral Democracy."

Governance 16 (1): 23 - 50.

Knight, Jack and James Johnson. 1994. "Aggregation and Deliberation: On the Possibility of Democratic Legitimacy.” Political Theory 22(): 277 - 296.

Knight, Jack and James Johnson. 1997. "What Sort of Equality Does Deliberative

Democracy Require?" In Bohman, James and William Rehg (eds.) Deliberative

Democracy: Essays on Reason and Politics. Cambridge, Mass.: MIT Press, pp. 279 319.

List, Christian. 2004. "The Discursive Dilemma and Public Reason.” Manuscript. http://personal.lse.ac.uk/list/PDF-files/PublicReason.pdf.

List, Christian and Robert Goodin. 2001. "Epistemic Democracy: Generalizing the

Condorcet Jury Theorem.” Journal of Political Philosophy 9(3): 277 - 306.

List, Christian and Philip Pettit. 2002. "Aggregating Sets of Judgments: An

Impossibility Result.” Economics and Philosophy 18: 89 - 110.

List, Christian and Philip Pettit. 2004. "Aggregating Sets of Judgments: Two Impossibility Theorems Compared.” Synthese 140(1-2): 207 - 235. 
Longino, Helen. 1987. Science as Social Knowledge. Princeton: Princeton University Press.

Longino, Helen. 2002. The Fate of Knowledge. Princeton: Princeton University Press. Manin, Bernard. 1987. “On Legitimacy and Political Deliberation.” Political Theory 15: $338-368$

May, Kenneth O. 1952. "A Set of Independent, Necessary, and Sufficient Conditions for Simple Majority Decision.” Econometrica 20(4): 680 - 84.

Mueller, Dennis. 1989. Public Choice II. Cambridge: Cambridge University Press. Parkinson, John. 2003. "Legitimacy Problems in Deliberative Democracy.” Political Studies 51: $180-196$.

Peter, Fabienne. 2007. “The Political Egalitarian's Dilemma.” Ethical Theory and Moral Practice, in press.

Pettit, Philip. 2001a. A Theory of Freedom. Oxford: Oxford University Press. Pettit, Philip. 2001b. "Deliberative Democracy and the Discursive Dilemma." Philosophical Issues 11: 268 - 299.

Postema, Gerald. 1995. "Public Practical Reason: An Archeology." Social Philosophy and Policy 12: 43 - 86.

Rawls, John. 1971. A Theory of Justice. Cambridge: Harvard University Press.

Rawls, John. 1993. Political Liberalism. New York: Columbia University Press.

Riker, William H. (1982): Liberalism against Populism. San Francisco: Freeman. Rousseau, Jean-Jacques. 1987 [1763]. "On the Social Contract". In Rousseau Basic Political Writings. Indianapolis: Hackett, pp. $141-227$.

Sen, Amartya. 1999a. Development as Freedom. New York: Knopf. Sen, Amartya. 1999b. "Democracy and Social Justice.” Paper presented at the Seoul Conference on Democracy, Market Economy and Development, February 26-27, 1999. 
Simmons, A. John. 1999. “Justification and Legitimacy.” Ethics 109: 739 - 771.

Simmons, A. John. 2001. Justification and Legitimacy. Cambridge: Cambridge

University Press.

Valadez, Jorge M. 2001. Deliberative Democracy, Political Legitimacy, and SelfDetermination in Multicultural Societies. Boulder: Westview Press.

Waldron, Jeremy. 1989. "Democratic Theory and the Public Interest: Rousseau and Condorcet Revisited.” American Political Science Review 83: 1322 - 1328.

Young, Iris Marion. 1989. "Polity and Group Difference: A Critique of the Ideal of Universal Citizenship.” Ethics 99(2): 250 - 274.

Young, Iris Marion. 1996. Communication and the Other: Beyond Deliberative

Democracy. In Benhabib, Seyla (ed.) Democracy and Difference. Princeton: Princeton University Press, pp. $120-135$.

Young, Iris Marion. 1997. "Difference as a Resource for Democratic Communication.” In Bohman, James and William Rehg (eds.) Deliberative Democracy: Essays on Reason and Politics. Cambridge, Mass.: MIT Press, pp. 383 - 406.

Young, Iris Marion. 2000. Inclusion and Democracy. Oxford: Oxford University Press. 